\title{
BMJ open Limited potential of school textbooks to prevent tobacco use among students grade 1-9 across multiple developing countries: a content analysis study
}

To cite: Saito J, Nonaka D, Mizoue T, et al. Limited potential of school textbooks to prevent tobacco use among students grade 1-9 across multiple developing countries: a content analysis study. BMJ Open 2013;3: e002340. doi:10.1136/ bmjopen-2012-002340

- Prepublication history for this paper are available online. To view these files please visit the journal online (http://dx.doi.org/10.1136/ bmjopen-2012-002340).

Received 13 November 2012 Revised 10 January 2013 Accepted 28 January 2013

This final article is available for use under the terms of the Creative Commons Attribution Non-Commercial 2.0 Licence; see http://bmjopen.bmj.com

For numbered affiliations see end of article.

\section{Correspondence to} Dr Daisuke Nonaka; laodaisuke@hotmail.co.jp

\section{ABSTRACT}

Objective: To evaluate the content of school textbooks as a tool to prevent tobacco use in developing countries.

Design: Content analysis was used to evaluate if the textbooks incorporated the following five core components recommended by the $\mathrm{WHO}$ :

(1) consequences of tobacco use; (2) social norms;

(3) reasons to use tobacco; (4) social influences and

(5) resistance and life skills.

Setting: Nine developing countries: Bangladesh, Cambodia, Laos, Nepal, Sri Lanka, Benin, Ghana, Niger and Zambia.

Textbooks analysed: Of 474 textbooks for primary and junior secondary schools in nine developing countries, 41 were selected which contained descriptions about tobacco use prevention.

Results: Of the 41 textbooks, the consequences of tobacco use component was covered in 30 textbooks $(73.2 \%)$ and the social norms component was covered in $19(46.3 \%)$. The other three components were described in less than $20 \%$ of the textbooks.

Conclusions: A rather limited number of school textbooks in developing countries contained descriptions of prevention of tobacco use, but they did not fully cover the core components for tobacco use prevention. The chance of tobacco prevention education should be seized by improving the content of school textbooks.

\section{INTRODUCTION}

Tobacco use is a significant public health issue among adolescents. In developing countries, approximately 68000 to 84000 adolescents start smoking every day, which accounts for $80 \%$ of all adolescents taking up smoking daily across the world. ${ }^{1}$

To prevent adolescents' use of tobacco, various initiatives have been undertaken in developing countries. Such efforts include

\section{ARTICLE SUMMARY}

Article focus

- An analysis of the content of school textbooks about tobacco use prevention in developing countries.

\section{Key messages}

- The descriptions on prevention of tobacco use were contained in a rather limited number of school textbooks in developing countries.

- Key components of tobacco prevention education were not fully described in the school textbooks.

Strengths and limitations of this study

- This is the first multicountry study to evaluate the content of school textbooks about tobacco use prevention in developing countries.

- Investigation was not done on whether better school textbooks made a difference.

raising the taxation on tobacco products, expanding smoke-free environments and conducting the Global Youth Tobacco Survey (GYTS) to understand adolescents' behaviour, knowledge and norms. ${ }^{2}$ Another widely implemented initiative worldwide has been school-based prevention education, which is recommended as an essential element of tobacco control programmes by the WHO. ${ }^{3}$ The WHO has proposed guidelines outlining six core components to prevent adolescents' use of tobacco through school-based education. ${ }^{3}$ These components include (1) consequences of tobacco use, (2) social norms, (3) reasons to use tobacco, (4) social influences, (5) resistance skills and (6) life skills.

In principle, school-based education has great potential to prevent tobacco use among adolescents. Though conclusive evidence of long-term effectiveness is still needed, school-based educational messages 
can reach large numbers of adolescents at the critical time for uptake of smoking. ${ }^{4}$ Especially in developing countries, the advantage of school-based education is compounding as the enrolment of the official age-group for a given level rapidly increases. In sub-Saharan Africa, for example, the enrolment rate increased from $56 \%$ in the 1990 s to $70 \%$ in $2006 .{ }^{5}$ While school-based programmes that incorporate the key components proposed by the WHO have been effective in reducing adolescents' use of tobacco in the short term, long-term effectiveness has been found to be limited. ${ }^{6}$ However, if the programmes were to include booster sessions that spanned the high school years, then they might arguably register long-term effects as well. ${ }^{7}$ Moreover, recent studies indicate a possibility to improve the effectiveness of school-based programmes by combining them with other programmes such as community interventions or mass media campaigns. ${ }^{8} 9$

School textbooks are the most commonly used and crucial educational resources, especially in developing countries. ${ }^{10}$ While various textbooks may contain information related to health, such information may in some cases not be supported by scientific evidence. ${ }^{11}$ Accordingly, the Unesco has proposed 'quality development' of school textbooks as one of the key strategies to achieve 'Education for All' by 2015. ${ }^{12}$ Yet school textbooks have been overlooked as a potential tool to prevent tobacco use among schoolchildren. Though some research has analysed the content of health-related textbooks, ${ }^{11} 13{ }^{14}$ little has been done to examine the content of school textbooks related specifically to tobacco use prevention. If the quality of school textbooks is poor in this regard, it may detract from opportunities to use them effectively in health education to avoid tobacco use among adolescents. The objective of this study was thus to evaluate whether the information in the textbooks being used for a cross-section of the developing world is covering the core components necessary for preventing tobacco use in these settings.

\section{METHODS}

\section{Textbook collection}

Textbooks were sampled between January 2009 and March 2010. We selected Bangladesh, Cambodia, Laos, Nepal, Sri Lanka, Benin, Ghana, Niger and Zambia for inclusion in the study because (1) tobacco control is still limited in these nine countries despite being a part of the 'Framework Convention on Tobacco Control' international treaty, (2) we have established relationships with local collaborators in these countries and (3) these local collaborators have forged strong partnerships with key education sector elements such as the Ministry of Education and the local education department. Local collaborators had knowledge of the textbooks used in public primary and junior secondary schools in the public sector. Some collaborators also contributed for reviewing of the textbooks. In Bangladesh, Cambodia,
Laos, Nepal, Sri Lanka and Zambia, there was only one textbook publisher that was authorised by the government to publish, so we decided to collect all the textbooks published by the authorised body. By contrast, in Benin, Ghana and Niger, where there were multiple authorised publishers, we decided to collect the textbooks deemed to be most commonly used in public schools on the basis of consultation with local experts. The collected textbooks covered all subjects including mathematics and language arts, as integrated health education is widely adopted in many countries. The target grades were 1-9, which correspond to primary and junior secondary school students in most countries. In Bangladesh and Nepal, however, as the junior secondary schools finish at grade 8 , we supplemented the grade 9 textbooks by adding textbooks from the first year of high school in these two countries. Additionally, although the final grade of the junior secondary schools is grade 10 in Niger and Benin, our examination did not extend through the grade 10 .

We obtained textbooks from bookshops, the Ministry of Education or through organisations authorised by the government to distribute textbooks to schools. In total, 474 textbooks were collected and included in the analyses; 70 textbooks came from Bangladesh, 37 from Cambodia, 63 from Laos, 69 from Nepal, 68 from Sri Lanka, 36 from Benin, 33 from Ghana, 57 from Niger and 41 from Zambia.

\section{Textbook examination}

Each of the textbooks was reviewed by two public health experts for content on the use of substances including alcohol, tobacco or drugs. The second reviewer checked the first reviewer's extracted information for soundness. In cases where the original textbook content was written in French or a local language, public health experts in each country identified relevant health-related contents in the textbooks and translated those portions into English. When a content or translation discrepancy was identified between the two reviewers, textbooks were re-examined for clarification. Finally, content related to tobacco use was selected for analysis. We categorised descriptions about general substance use as tobacco use descriptions only where the chapter included an explanation that specifically mentioned tobacco use.

\section{Content analysis}

We conducted a content analysis using descriptive statistics, with proportions calculated from quantitative research findings. We categorised the textbook content using five core components defined according to the WHO guidelines: (1) consequences of tobacco use (eg, heart disease and cancer); (2) social norms (eg, to decrease social acceptability and correct overestimation of peers' smoking habits); (3) reasons to use tobacco (eg, a desire for acceptance and stress reduction); (4) social influences (eg, promoting tobacco use through peers, family and the media) and (5) resistance and life skills (eg, to resist 
such social influences and avoid tobacco use). ${ }^{3}$ The WHO guidelines 'Information Series on School Health, Tobacco Use Prevention' present six components encapsulating school-based strategies for preventing tobacco use among adolescents. Out of these, the resistance skills and life skills components were combined in this study, as these skills are typically taught together. For instance, specific skills to resist pressure to smoke are taught as the application of general assertive skills. ${ }^{15}$ After categorising the textbook content according to the five core components, we developed subcategories based on the WHO guidelines and evidence from previous research into which the content was then divided. The number of textbooks containing each sub-category of the content and their percentages out of 41 textbooks were calculated (table 2). As one textbook can include several components/subcategories, the sum of all individual component/sub-category counts can exceed the total number of textbooks.

\section{RESULTS}

\section{Characteristics of the target textbooks}

Out of the 474 textbooks collected from nine countries, $41(8.6 \%)$ contained descriptions of prevention of tobacco use. Of these, $35(85.4 \%)$ were in science-related subjects and six $(14.6 \%)$ were in language-related or religion-related subjects (table 1 ). In each country, a textbook within at least one subject included content aimed at tobacco use prevention, ranging from one subject in Sri Lanka (Health) to four subjects in Zambia (Science, Sociology, Technology and English). Additionally, 16 of the 41 textbooks $(39.0 \%)$ contained content falling outside the scope of the five core components, such as descriptions covering cessation of tobacco use.
The grade in which tobacco use prevention education was initiated varied widely among the target countries. The median was grade 3, but data points ranged from grade 1 in Cambodia and Zambia, to grade 8 in Sri Lanka (table 1). Regarding booster sessions, the consequences of tobacco use component and social norms component were taught in more than two grades in eight countries and in five countries, respectively. The other three components were not taught across multiple grades or were taught in only one country.

\section{Characteristics of the textbook content}

Among the five core components of tobacco prevention education (table 1), the average number of components covered in any textbook was three, ranging from one in Sri Lanka to five in Laos. The consequences of tobacco use component was contained in at least one textbook in all nine countries; the other components were only covered in some of the target countries. Regarding the distribution of each of the five components (table 2), the consequences of tobacco use component was covered in 30 textbooks $(73.2 \%)$ while the social norms component was covered in 19 textbooks (46.3\%). The other three components were incorporated in less than $15 \%$ of the textbooks (reasons to use tobacco: $9.8 \%$; social influences: $9.8 \%$; resistance and life skills: $14.6 \%$ ).

The distribution of content across the sub-categories of each component ranged widely. Within the consequences of tobacco use component, physiological consequences such as 'tobacco use can result in exacerbation of asthma', which was included in 28 (68.3\%) textbooks, was the most frequently described subcategory. Social consequences, such as 'smoking can cause a financial burden', was the second most frequently

Table 1 Subjects and grades of textbook content with components for tobacco use prevention in the countries surveyed (number of grades)

\begin{tabular}{|c|c|c|c|c|c|}
\hline & $\begin{array}{l}\text { Consequences of tobacco } \\
\text { use }\end{array}$ & Social norms & $\begin{array}{l}\text { Reasons to } \\
\text { use tobacco }\end{array}$ & $\begin{array}{l}\text { Social } \\
\text { influences }\end{array}$ & $\begin{array}{l}\text { Resistance } \\
\text { and life skills }\end{array}$ \\
\hline Bangladesh & $\begin{array}{l}\text { Hindu religious studies (6) } \\
\text { Islamic studies (6), Science (8) }\end{array}$ & $\begin{array}{l}\text { Hindu religious studies (6) } \\
\text { Islamic studies (6) }\end{array}$ & & & \\
\hline Cambodia & Science $(7,9)$ & Science $(1,7,9)$ & & & Science (9) \\
\hline Laos & Language (2), Sociology (5) & Science (8), Sociology (4) & Sociology (5) & Sociology (5) & Sociology (5) \\
\hline Nepal & $\begin{array}{l}\text { Civic and social studies (6) } \\
\text { Science (3-8) }\end{array}$ & $\begin{array}{l}\text { Civic and social studies (6) } \\
\text { Science }(3,5-8)\end{array}$ & & Science (5) & Science $(5-8)$ \\
\hline Sri Lanka & Health (8) & & & & \\
\hline Benin & $\begin{array}{l}\text { Biology (9) } \\
\text { French (7) } \\
\text { Science (6) }\end{array}$ & & & French (7) & \\
\hline Ghana & $\begin{array}{l}\text { Sociology }(5-6,9) \text {, } \\
\text { Sciences }(4,7)\end{array}$ & Sociology $(7,9)$ & Sociology $(6,9)$ & Sociology (7) & \\
\hline Niger & $\begin{array}{l}\text { Biology (9) } \\
\text { English (4) } \\
\text { Reading and writing (3) }\end{array}$ & & English (4) & English (4) & \\
\hline Zambia & $\begin{array}{l}\text { Science }(3,4,7) \\
\text { Sociology }(2) \\
\text { Technology }(6,7)\end{array}$ & $\begin{array}{l}\text { English (7) } \\
\text { Technology }(1,3,6)\end{array}$ & Science(7) & & \\
\hline
\end{tabular}


Table 2 Content of descriptions regarding tobacco use among textbooks in the countries surveyed $(n=41)$

\begin{tabular}{|c|c|c|}
\hline Content & $\mathbf{n}$ & Percen \\
\hline \multicolumn{3}{|l|}{ Consequences of tobacco use ( $n=30,73.2 \%)$} \\
\hline Physiological consequences & \multicolumn{2}{|c|}{2868.3} \\
\hline Social consequences & \multicolumn{2}{|c|}{1741.5} \\
\hline Psychological consequences & \multicolumn{2}{|c|}{819.5} \\
\hline \multicolumn{3}{|l|}{ Social norms $(n=19,46.3 \%)$} \\
\hline $\begin{array}{l}\text { The norm that tobacco use is not socially } \\
\text { accepted }\end{array}$ & \multicolumn{2}{|c|}{1536.6} \\
\hline $\begin{array}{l}\text { The norm that tobacco use should be } \\
\text { controlled }\end{array}$ & \multicolumn{2}{|c|}{819.5} \\
\hline $\begin{array}{l}\text { The norm that most peers do not use } \\
\text { tobacco }\end{array}$ & 1 & 2.4 \\
\hline \multicolumn{3}{|l|}{ Reasons to use tobacco $(n=4,9.8 \%)$} \\
\hline Acceptance by peers & 4 & 9.8 \\
\hline Coping with stress & 3 & 7.3 \\
\hline Curiosity & 2 & 4.9 \\
\hline Being strong & 1 & 2.4 \\
\hline $\begin{array}{l}\text { Unknown (open question without any } \\
\text { answers) }\end{array}$ & 1 & 2.4 \\
\hline \multicolumn{3}{|l|}{ Social influences $(n=4,9.8 \%)$} \\
\hline Influence by adults & 3 & 7.3 \\
\hline Influence by general society & 2 & 4.9 \\
\hline Influence by media & 1 & 2.4 \\
\hline Influence by peers & 1 & 2.4 \\
\hline \multicolumn{3}{|l|}{ Resistance and life skills ( $n=6,14.6 \%)$} \\
\hline $\begin{array}{l}\text { The skill to avoid making friends who use } \\
\text { tobacco }\end{array}$ & 4 & 9.8 \\
\hline $\begin{array}{l}\text { The skill to advise tobacco-using } \\
\text { peers/family to quit }\end{array}$ & 3 & 7.3 \\
\hline $\begin{array}{l}\text { The skill to utilise leisure time for other } \\
\text { activities }\end{array}$ & 2 & 4.9 \\
\hline The skill to avoid curiosity about tobacco & 1 & 2.4 \\
\hline $\begin{array}{l}\text { The skill to avoid believing promotion } \\
\text { messages }\end{array}$ & 1 & 2.4 \\
\hline $\begin{array}{l}\text { The skill to avoid thinking about trying } \\
\text { tobacco use just once }\end{array}$ & 1 & 2.4 \\
\hline $\begin{array}{l}\text { The skill to avoid imitating others' use of } \\
\text { tobacco }\end{array}$ & 1 & 2.4 \\
\hline The skill to reject offers of tobacco by peers & 1 & 2.4 \\
\hline
\end{tabular}

included sub-category in this domain; it appeared in 17 textbooks $(41.5 \%)$.

\section{DISCUSSION}

Our results suggest that textbooks in the countries surveyed do not comprehensively cover or systematically integrate the core components necessary for effective youth tobacco prevention education.

The component found in the majority (30 of 41) of textbooks was the consequence of tobacco use factor. This finding suggests that knowledge-based education is still a common type of tobacco prevention education in schools within the target countries. Knowledge about the consequences of tobacco use is one of the core components of tobacco use prevention laid down by the WHO guidelines. ${ }^{3}$ Yet such knowledge alone has limited impact when it comes to reducing smoking behaviour among adolescents. ${ }^{6}{ }^{16}$ Adolescents tend to overestimate the prevalence of peer smoking and their estimates can impact on their smoking behaviour. ${ }^{17}{ }^{18}$ However, social norms descriptions were often lacking from the textbooks in the target countries, especially those covering the norm of correcting overestimation.

The remaining three components (reasons to use tobacco, social influences and resistance and life skills) were described much less frequently in the textbooks. Even descriptions about peer pressure were included in only $12.2 \%$ of the target textbooks ('Acceptance by peers' for the reasons to use tobacco component and 'Influence by peers' for the social influences component), despite peer pressure being one of the strongest predictors of tobacco using behaviour among adolescents globally. ${ }^{19}$ In addition, all of the descriptions of resistance and life skills only explained the behaviour and none included any application of training methods, such as role-playing activities, for developing these skills. ${ }^{20}$

The social influences approach has been considered to be widely effective in reducing adolescent smoking prevalence and initiation, and many tobacco prevention programmes have employed this approach in the last three decades. ${ }^{21}$ First, adolescents learn about the potential influences on tobacco using behaviour they are likely to receive through their peers, family members and the media. $^{21}$ Once students recognise high-risk situations, they learn practical approaches to handling or avoiding such social influences. ${ }^{21}$ Normative education promotes a norm against tobacco use among peers, which is a necessary norm for skills training to deal with peer pressures, ${ }^{22}$ and corrects their misperceptions that tobacco use is common among peers. Knowledge-based education is expected to support this normative education. Thus, all of the five core components need to be systematically integrated into the textbooks of certain subjects in order to reduce or prevent youth tobacco use.

In the case of Laos, although all five components were included in the targeted textbooks, each component was separately contained in the textbooks for several subjects and grades. For example, social norms and consequences of tobacco use components were contained in the textbooks of several subjects for different grades. However, as knowledge about the consequences of tobacco use is expected to support normative education, the corresponding sessions are expected to be linked within the framework of 'tobacco prevention education'.

Content geared towards tobacco use prevention appeared in primary school (grades 1-5 in Bangladesh and Nepal, and grades 1-6 in the remaining countries) textbooks in all of the countries surveyed except for Bangladesh and Sri Lanka. As school-based prevention education targets all students in the classroom, the education should be implemented before the onset of tobacco use. Notably, some students in developing countries start using tobacco earlier than junior secondary school. In Ghana and Malawi, for instance, about $40 \%$ of smokers aged 13-15 years had smoked their first cigarette 
before the age of $10 .^{23}$ Although junior secondary school students are the main focus of research about school-based prevention, ${ }^{24}$ the effects of smoking prevention programmes during primary school have been shown to survive the transition to secondary schools. ${ }^{25}$ A critical time period for implementation of tobacco prevention education in these countries might thus be primary school.

In addition, the content on tobacco use prevention was taught repeatedly in multiple grades. Such booster sessions have been shown to be effective only if the programmes include core components like social influences, social norms and resistance skills, and if the same content is boosted over multiple years. ${ }^{21}$ In the present study, however, essentially only the consequences of tobacco use and/or social norms components were contained in the textbooks across multiple grades. In addition, the targeted subject of booster sessions in each component was not always the same in each countryan inconsistent approach unlikely to be effective. ${ }^{7}$ These results suggest that booster sessions in target countries might, in their current format, have a limited effect in preventing tobacco use among students in grades 1-9.

Overall, our findings revealed that most of the WHO-specified key components of tobacco use prevention were not well reflected in the textbooks used in grades 1-9 in the developing countries surveyed. Tobacco issues need to be integrated into the curriculum within the framework of 'tobacco prevention education', because the key components of tobacco prevention education were covered only partially in the existing textbooks for various subjects and grades. Booster sessions should also be encouraged and covered in the textbooks. Moreover, evidence shows that the combination of a school-based curriculum and mass media messages on tobacco industry manipulation has had a great impact in preventing tobacco use among adolescents. ${ }^{9}$ Although evidence on the effectiveness of mass media campaigns comes mainly from developed countries, a similar impact can also be expected among adolescents in developing countries, as they are similarly receptive to tobacco marketing. ${ }^{26}$

Such insights must, of course, be considered in the context of five primary limitations associated with this study. First, investigation was not done into whether better school textbooks made a difference. In this study, we evaluated if school textbooks incorporate the core components as necessary to prevent tobacco use. However, we did not investigate the impact of such school textbooks which cover all the core components on preventing or reducing adolescents' use of tobacco. Further study is necessary to assess whether the content of school textbooks actually makes a difference in tobacco use among students as well.

Second, the content of textbooks alone does not necessarily reflect the reality of school-based education. Other forms of educational resources designed to prevent tobacco use may also be available in schools beyond textbooks. In Cambodia, for example, an international NGO has been providing school-based tobacco use prevention education through drama performances. ${ }^{27}$ Nevertheless, school textbooks are a central and important resource for teachers, especially in developing countries where such resources tend to be limited. ${ }^{10}$ In addition, textbooks are available for all schools nationwide and are more likely to be sustainable than educational resources provided by donors, which sometimes target limited areas of the country and may be associated with one-shot programmes.

Third, the study lacked data on high school textbooks. One of the key factors linked to long-term effects through school-based programmes is providing booster sessions in high schools. ${ }^{7}$ Therefore, the results of this study might include underestimations or overestimations of true content prevalence due to the somewhat limited reach of our data collection. However, because more than half of the children in the target countries, with the exception of Sri Lanka, do not go on to high schoollevel education, data on high school textbooks would seem to be of limited value.

Fourth, although two reviewers were involved in identifying the textbook descriptions about substance use, the review was not independently done; rather, the second reviewer checked the first reviewer's extracted information for soundness. Thus, the results of this study might be biased compared to those produced by independent reviews.

Finally, the policy aspect of school regulations regarding tobacco use was not taken into account. The relevant factors in this vein might have included, for example, the implementation of tobacco use restrictions in schools. Since a well-implemented school policy is an important component of school-based health promotion, ${ }^{28}$ further study is necessary to assess the influence of school policy on tobacco use among students as well.

\section{CONCLUSIONS}

The descriptions of prevention of tobacco use were contained in quite a limited number of textbooks in the nine target countries. In addition, the content did not comprehensively cover the necessary core components as outlined by the WHO guidelines for tobacco prevention education. Furthermore, they were not integrated systematically with sufficient boosters across grades 1-9. Most of the WHO-specified key components of tobacco use prevention were limited in their inclusion in textbooks across the target countries, or were absent altogether. Thus, the poor content of tobacco use is, in effect, squandering rare opportunities to educate students grade 1-9 in developing countries. Improving school textbook content could contribute to more effective prevention of tobacco use among students in these settings.

Author affiliations

${ }^{1}$ Department of Community and Global Health, Graduate School of Medicine, The University of Tokyo, Tokyo, Japan 
${ }^{2}$ Department of Parasitology and International Health, Graduate School of Medicine, University of the Ryukyus, Okinawa, Japan

${ }^{3}$ Department of Epidemiology and Prevention, Clinical Research Center, National Center for Global Health and Medicine, Tokyo, Japan

${ }^{4}$ Graduate School of International Health Development, Nagasaki University, Nagasaki, Japan

${ }^{5}$ Department of International Medical Cooperation, National Center for Global Health and Medicine, Tokyo, Japan

${ }^{6}$ UChicago Research Bangladesh Ltd, Dhaka, Bangladesh

${ }^{7}$ The Walter H. Shorenstein Asia-Pacific Research Center, Freeman Spogli Institute of International Studies, Stanford University, Stanford, USA

${ }^{8}$ Parasitology Department, Noguchi Memorial Institute for Medical Research, University of Ghana. Legon, Accra, Ghana

Acknowledgements The authors would like to thank their local collaborators as well as officials from the health and education sectors in the participating countries for their contributions and support.

Contributors JS performed the analysis and drafted the manuscript. DN, TM, $\mathrm{JK}$ and MJ conceived of the study and participated in its design and coordination. DN and MJ helped to draft the manuscript. DN, ACJ, SS, KK, SHE, SY and IA collected the data and helped to perform the analysis. All authors read and approved the final manuscript.

Funding This study was funded by the Ministry of Health, Labour and Welfare of Japan (research grant number: H21-chikyukibo-wakate-011) and the National Center for Global Health and Medicine, Japan (research grant number: 24S2).

Competing interests None.

Provenance and peer review Not commissioned; externally peer reviewed.

Data sharing statement No additional data are available.

\section{REFERENCES}

1. World Bank. Curbing the epidemic: governments and the economics of tobacco control. The International Bank for Reconstruction and Development 1999. http://www.usaid.gov/policy/ads/200/tobacco.pdf (accessed 20 Aug 2012).

2. Warren CW, Jones NR, Peruga A, et al. Global youth tobacco surveillance, 2000-2007. MMWR Surveill Summ 2008;57:1-28.

3. WHO. Information Series on School Health: tobacco use prevention: an important entry point for the development of a health-promoting school. World Health Organization, 1998. http://www.who.int/ school_youth_health/media/en/89.pdf (accessed 20 Aug 2012).

4. Park H, Dent $\mathrm{C}$, Abramsohn E, et al. Evaluation of California's in-school tobacco use prevention education (TUPE) activities using a nested school-longitudinal design, 2003-2004 and 2005-2006. Tob Control 2010;19:143-50.

5. UNESCO. Overcoming inequality: why governance matters. Education for all global monitoring report. United Nations Educational, Scientific and Cultural Organization, 2009. http://unesdoc.unesco.org/images/0017/001776/177683e.pdf (accessed 20 Aug 2012).

6. Thomas RE, Perera R. School-based programmes for preventing smoking. Cochrane Database Syst Rev 2006;19:CD001293.

7. Flay BR. The promise of long-term effectiveness of school-based smoking prevention programs: a critical review of reviews. Tob Induc Dis 2009;5:7.
8. Longshore D, Ghosh-Dastidar B, Ellickson PL. National youth anti-drug media campaign and school-based drug prevention: Evidence for a synergistic effect in ALERT Plus. Addict Behav 2006;31:496-508.

9. Brinn MP, Carson KV, Esterman AJ, et al. Mass media interventions for preventing smoking in young people. Cochrane Database Syst Rev 2010;11:CD001006.

10. Mohammad R, Kumari R. Effective use of textbooks: a neglected aspect of education in Pakistan. J Educ Int Dev 2007;3:5.

11. Barrio-Cantalejo I, Ayudarte-Larios L, Hernán-García M, et al. Are the health messages in schoolbooks based on scientific evidence? A descriptive study. BMC Public Health 2011;11:54-64.

12. UNESCO. A comprehensive strategy for textbooks and learning materials. United Nations Educational, Scientific and Cultural Organization, 2005. http://unesdoc.unesco.org/images/0014/001437/ 143736eb.pdf (accessed 20 Aug 2012).

13. Nonaka D, Jimba M, Mizoue T, et al. Content analysis of primary and secondary school textbooks regarding malaria control: a multi-country study. PLOS ONE 2012;7:e36629.

14. Nomoto M, Nonaka D, Mizoue T, et al. Content analysis of school textbooks on health topics: a systematic review. Biosci Trends 2011;5:61-8.

15. Botvin GJ, Griffin KW, Diaz T, et al. Drug abuse prevention among minority adolescents: posttest and one-year follow-up of a school-based preventive intervention. Prev Sci 2001;2:1-13.

16. Botvin GJ, Griffin KW, Diaz T, et al. Smoking initiation and escalation in early adolescent girls: one-year follow-up of a school-based prevention intervention for minority youth. J Am Med Womens Assoc 1999;54:139-43.

17. Sussman S, Dent CW, Mestel-Rauch J, et al. Adolescent nonsmokers, triers, and regular smokers' estimates of cigarette smoking prevalence: when do overestimations occur and by whom? $J$ Appl Soc Psychol 1988;18:537-51.

18. Ellickson PL, Bird CE, Orlando M, et al. Social context and adolescent health behavior: does school-level smoking prevalence affect students' subsequent smoking behavior? J Health Soc Behav 2003;44:525-35.

19. Tyas SL, Pederson LL. Psychosocial factors related to adolescent smoking: a critical review of the literature. Tob Control 1998:7:409-20.

20. Hansen WB. School-based substance abuse prevention: a review of the state of the art in curriculum, 1980-1990. Health Educ Res 1992;7:403-30.

21. Botvin GJ. Preventing drug abuse in schools: social and competence enhancement approaches targeting individual-level etiologic factors. Addict Behav 2000;25:887-97.

22. Donaldson SI, Sussman S, MacKinnon DP, et al. Drug abuse prevention programming. Am Behav Sci 1996;39:868-83.

23. Global Youth Tobacco Survey Collaborative Group. Tobacco use among youth: a cross country comparison. Tob Control 2002;11:252-70.

24. Botvin GJ, Griffin KW. School-based programmes to prevent alcohol, tobacco and other drug use. Int Rev Psychiatry 2007:19:607-15.

25. Crone M, Spruijt R, Dijkstra N, et al. Does a smoking prevention program in elementary schools prepare children for secondary school? Prev Med 2011:52:53-9.

26. Saito J, Yasuoka J, Poudel KC, et al. Receptivity to tobacco marketing and susceptibility to smoking among non-smoking male students in an urban setting in Lao PDR. Tob Control. Published Online First: 26 May 2012. doi: $10.1136 /$ tobaccocontrol-2011-050125

27. Adventist Development and Relief Agency. Cambodia Annual Report 2001. http://www.adracambodia.org/annual-review/Review\%202001. pdf (accessed 20 Aug 2012).

28. Evans-Whipp T, Beyers JM, Lloyd S, et al. A review of school drug policies and their impact on youth substance use. Health Promot Int 2004;19:227-34. 